Civil Engineering Volume 169 Issue CE5

Managing safely in humanitarian projects

Brown
Proceedings of the Institution of Civil Engineers Civil Engineering 169 May 2016 Issue CE5 Pages 56-62 http://dx.doi.org/10.1680/jcien.15.00057 Paper 1500057

Received 31/08/2015 Accepted 13/01/2016

Keywords: design methods \& aids/developing countries/ health \& safety
. Qe

\title{
Managing safely in humanitarian projects
}

Andrew Brown MEng, MInstRE, TechIOSH, MAPM

Project Manager and Construction Health \& Safety Lead (Capital Projects),

Natural Resources Wales, UK; Volunteer with Engineers For Overseas

Development, UK

The recent update to the UK Construction (Design and Management) Regulations has brought into focus the responsibility of all those involved in construction projects to construct safely. This paper uses experience of scoping, designing and constructing development projects in Costa Rica and Uganda to discuss the role of clients and designers in humanitarian projects in ensuring safety, and the methods that can be used to encourage safe working practices. Humanitarian projects are often constructed with local labour, but designed and specified elsewhere. Consideration at the early stage should be given to both the end user and those carrying out construction when selecting materials, method and structural forms. Although it is unreasonable to expect a change in a country's attitude towards construction risk in a single project, a variety of methods can be employed to educate, train and incentivise local labour forces to improve awareness and their safety culture.

\section{Introduction}

Construction is considered one of the world's most dangerous industries: it is estimated that over 60000 people a year die on construction sites. The number of construction fatalities in Great Britain has been steadily declining since the introduction of the Health and Safety at Work Act in 1974 (HSE, 2014) where improvements in risk awareness, working method and legislation have combined to improve safety.

Unfortunately the improvements have yet to be seen in the developing world where risk awareness is low, working practices poor and legislation weak. It is unreasonable to think that individual humanitarian projects alone can change a nation's safety culture, but by considering risks and hazards early enough improvements can be made.

All construction projects follow a similar path from inception to completion, starting with identifying and reviewing delivery options, to the selection and construction of the preferred solution. Risks in the latter stages can be reduced significantly if they are considered early. The client, designer and charity can play an important role in reducing risk to those who construct, operate and maintain a structure through this early consideration.

It is recognised that as some humanitarian projects may be reactive and urgent in nature, they will have a shortened planning cycle. As a result, the steps and considerations described in this paper may not be applicable to emergency works. However, where reactive work can be planned in advance, as in some military and flood defence applications, the design considerations outlined in this paper can and should be made.

The aim of this paper is to show how safety in humanitarian projects can be improved by applying the principles of the UK Construction (Design and Management) Regulations 2015 (HMG, 2015), referred to hereafter as the CDM regulations.
These principles are considering risk early, communicating remaining risks and above all proportionality. The intent is not to describe the application of the CDM regulations to humanitarian projects verbatim, but how they can be adapted to eliminate hazards and reduce risk.

\section{Project process}

Safety should be considered throughout the project lifecycle. The earlier hazards are considered, the more easily they can be reduced or eliminated. Designing out hazards is good practice in the developed world, but with a lower risk awareness and poorer safety culture, early consideration is even more crucial.

All projects follow a series of similar steps, as outlined in Table 1 . It is normal for feasibility and design to be completed in

\begin{tabular}{|c|c|}
\hline Stage & Description \\
\hline Feasibility & $\begin{array}{l}\text { Involves the setting of project objectives and the review of } \\
\text { options in such criteria as technical feasibility and cost to } \\
\text { achieve those. }\end{array}$ \\
\hline Design & Takes the preferred option to a constructible design. \\
\hline $\begin{array}{l}\text { Construction } \\
\text { planning }\end{array}$ & $\begin{array}{l}\text { Develops the plan by which the design will be delivered } \\
\text { and involves the programming of works and the planning } \\
\text { of procurement. }\end{array}$ \\
\hline Construction & $\begin{array}{l}\text { Construction of the preferred option and involves the } \\
\text { hiring of workers, site set-up and construction. }\end{array}$ \\
\hline $\begin{array}{l}\text { Operation and } \\
\text { maintenance }\end{array}$ & $\begin{array}{l}\text { Takes place after construction completion and is the daily } \\
\text { use of the completed structure. This may be carried out by } \\
\text { the development organisation or handed over to the local } \\
\text { community. }\end{array}$ \\
\hline
\end{tabular}

Table 1. Common project stages 
a developed country in advance of construction in the developing country. For emergency works, stages 1 and 2 are likely to have been completed during contingency planning exercises prior to an event, and stage 3 will be dramatically reduced as mobilisation will be, by necessity, rapid. The duration of stages 4 and 5 will vary, depending on circumstances.

\subsection{Feasibility}

The primary step is to review the initial brief to identify constraints and confirm the achievability of the objectives. As well as those stated, there will be additional constraints that need to be taken into account; safety is commonly one of these.

As options are explored and developed, the project manager should consider who is at risk and how the structure will operate on a daily basis. This will allow a preferred option to be reached that suits the operational activities and does not introduce hazards into the normal working environment.

\subsection{People at risk}

The first step to designing out risk is to identify who is at risk, both during construction and in the operational phase. The impact on third parties should also be considered throughout the project's lifecycle.

Examples of affected groups include the following.

- Workers - people who will carry out the construction, likely to be local labour, as shown in Figure 1. This group will be exposed to risks during construction, such as manual handling, working at height and handling hazardous materials.

- Operators - those who will carry out the daily operation of the structure post construction. This group of people will be exposed to risks such as confined spaces or slips trips and falls from uneven surfaces that remain.

- Maintainers - those who will maintain the structure post construction. This differs from routine operation and if not considered can expose maintainers to high risk such as working at height.

- Public - the public are at risk during construction and postconstruction phases. The risk during construction is magnified in humanitarian projects as it will attract a lot of interest from the local community. Children are especially curious and the posting of lookouts to keep them at a safe distance is advised. This was a lesson learnt in Uganda when, on the way home from school, children stopped to watch the erection of roof trusses from as close as they could physically get to the building.

\subsection{Daily operation and consideration of the end user}

Once it has been identified who is at risk, the operational processes that will be undertaken in the project management structure need to be considered and understood. By detailing the daily routine, asking how the task will be undertaken will allow elements of design to be included such as a loading platform or a strengthened beam for weighing grain sacks.

For a simple structure such as a grain store, questions should be asked such as how will the grain be stored? Will it be loose or in bags? How will grain be brought to the store? Will it be by vehicle? How will grain be weighed? What administration is required?

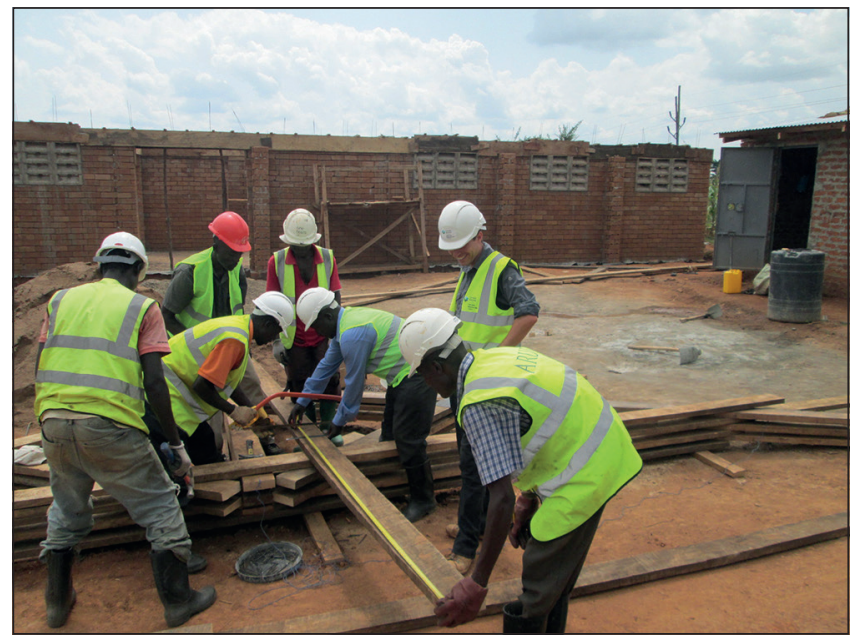

Figure 1. Ugandan workers

Involvement of the operator should be sought at this stage; however, this may be problematic if the design is taking place away from the community.

Tailoring the design to the daily operation will reduce risks to those carrying it out and will reduce the need for modifications, reducing risk and cost. Some suggested approaches currently being applied in the design of an Aids testing and community medical centre are to use process diagrams, community questionnaires and visits to similar structures as good ways to understanding the processes involved.

\section{Design}

The design phase of a humanitarian project is where the biggest reduction in risk can be made. Careful consideration of the enduser, the materials selected and how the structure is built can reduce the safety measures required during construction and subsequently throughout the life of the structure. While making these considerations, the hierarchy outlined in Section 3.1 should be used to assess options.

\subsection{Hierarchy of risk control}

The hierarchy of risk control is a simple and well-known method of assessing risk responses. It still forms a part of the CDM 2015 regulations as the more detailed general principles of prevention (CITB, 2016); however, the simpler eliminate, reduce, isolate, control, personal protective equipment (PPE) and discipline hierarchy familiar to many is a suitable tool (Table 2).

The hierarchy is commonly split into two groups: collective measures and individual measures. The first group, eliminate, reduce and isolate, are collective controls - passive solutions that do not rely on individuals to make a decision. The second group, control, PPE and discipline, require individuals to adhere to procedures to stay safe. It is important to find solutions that sit in the collective group, especially in humanitarian projects where the awareness of risk is lower and individual control measures are unlikely to be maintained. 


\subsection{Maintenance}

Maintenance requirements are linked to the choice of materials, as described in Section 3.3, but in addition the location and accessibility of certain elements need to be considered. Maintenance practices acceptable in the UK are unlikely to be fit for purpose in the developing world. Working at height practice is a good example of this.

In the developed world large scaffolds, mobile elevated working platforms or suspended cleaning baskets are a common sight. As shown in Figure 2 scaffolding commonly employed in Uganda is much less sophisticated or not as safe as that in the UK. Consequently, it is advisable to seek alternative options that reduce the requirement to work at height or remove the need all together.

\subsection{Materials}

The choice of material and finish will dictate both the maintenance requirements and the degree of construction risk. From a maintenance perspective, consideration should be given to the following.

- Design life - how long will the component last? Could a component be selected with a longer life, reducing the need for it to be repaired or replaced? Consider for example roofing

\begin{tabular}{|c|c|}
\hline Risk control & Comment \\
\hline Eliminate & $\begin{array}{l}\text { Where possible eliminate the risks associated with the } \\
\text { hazards }\end{array}$ \\
\hline Reduce & Reduce the amount of hazard or exposure to it \\
\hline Isolate & Prevent contact with the hazard with physical barriers \\
\hline Control & $\begin{array}{l}\text { Control access to the hazard through safe systems of } \\
\text { work such as permit systems }\end{array}$ \\
\hline $\begin{array}{l}\text { Personal protective } \\
\text { equipment }\end{array}$ & This should be the final resort for managing hazards. \\
\hline Discipline & $\begin{array}{l}\text { Engendering discipline into the workforce to operate } \\
\text { safely in adhering to and maintaining the above }\end{array}$ \\
\hline
\end{tabular}

Table 2. Hierarchy of risk control

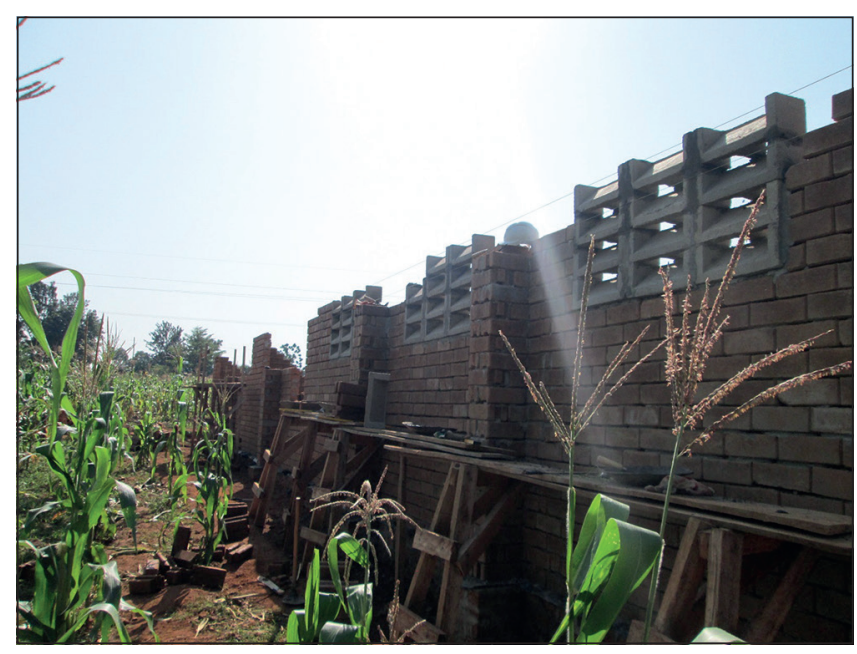

Figure 2. Ugandan scaffolding material where a lighter, cheaper option could offer a cost saving: it may only last for 5-10 years compared to a heavier duty option that lasts for 20-25 years, reducing the need for future replacement. If the component has a shorter design life than the overall structure, then consideration must be given as to how that component will be replaced.

- Failure mechanism - will the component fail gradually or suddenly? Will it give warning that it requires refurbishment and allow for a safe replacement method to be planned?

- Location on the structure - consideration should be given to where the component is located on the structure. Materials that require treatment or painting at regular intervals should be kept at lower levels, where they are easier to access. Components at height should be designed to have a longer design life or provided with a method of access.

- Criticality to the design - consideration should be given to the importance of a component to the success of the design. Supply of complicated or specialist items is likely to be problematic in a developing country, or items that are easy to obtain in a developed country may not be readily available. Any item that the design relies on for success must be readily available, easily replaced or have a long design life.

A good example of criticality was experienced during construction of a grain store in rural Uganda. Thermal analysis identified that, to reduce temperatures in the storeroom, the lightest finish roofing material should be selected, preferably white. In the initial design this was critical to maintaining a cool temperature inside the store. Should temperatures be too hot then the grain would spoil and be worthless. Following an extensive search of available roofing materials, it was established that white was not available, but greens and reds were readily available. The alternative colours, along with painting roof sheets white, were considered.

The considerations made by the project team were as follows.

- The white finish would need to be maintained and it is reasonable to assume that, as white sheets were not available during the construction, they would not be available when replacement was required, meaning that the roof would need repainting.

- Galvanised metal sheeting was standard so the paint would probably be solvent based, hazardous to health, dangerous to the environment and flammable.

- To achieve a reasonable life span the paint would need to be professionally applied with considerable preparation to the base material.

- Clear working at height risk would be introduced to the end user. How regularly access would be required would depend on the paint selected.

All activities in the UK could be controlled and the risks managed, but this would not be straightforward in Uganda. In this example the project team chose to select a light-green roof sheet readily available off the shelf, which offered a slightly lower thermal performance but a durable finish. The criticality of the roof finish was reduced by increasing the area of ventilation within the building. This saved both time and money during the construction and reduced the risk to those maintaining the structure - local metal painters. Figure 3 shows the completed structure. 


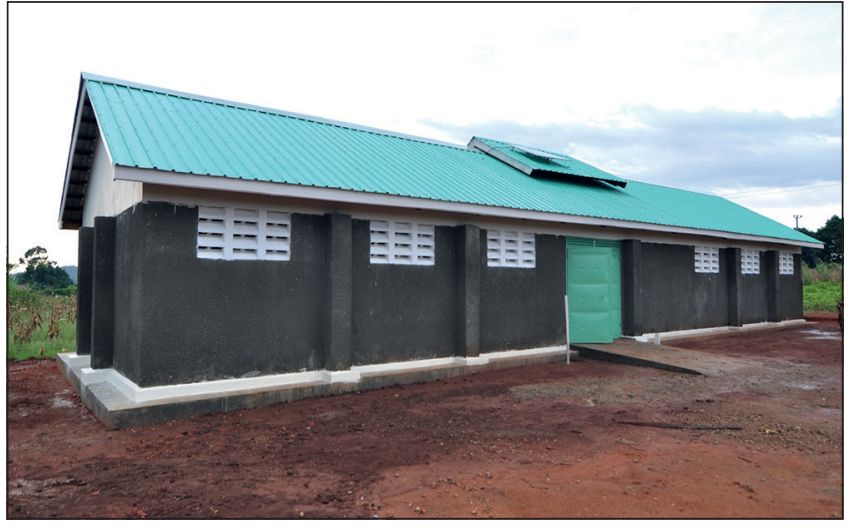

Figure 3. Grain store

\subsection{Buildability}

Designers should consider how the structure they have designed will be constructed. It is good practice to discuss the construction method and sequence with experienced contractors.

Finding a contractor experienced in the construction techniques of the country of the humanitarian project can be difficult if the project is not being designed in that country. If this is the case then the principle of simplicity should be adopted, in that the simplest construction method should be assumed. In many parts of the developing world this will be by hand, because plant, fuel and trained operators are likely to be few and far between and costly.

Some factors to consider are as follows.

- Simplifying the design, by adopting a simpler foundation system, for example. Adopting load-bearing piers instead of using the floor slab to reduce the amount of reinforcement and shuttering required.

- Reducing the weight of structural elements such as roof trusses that need to be lifted into position.

- Reducing the amount of concrete, masonry and especially excavation, which is time consuming in the hard soils of eastern Africa.

For the construction of the grain store mentioned in Section 3.3 and shown in Figure 3 the project team identified areas of the design that could cause problems during construction and held a construction workshop prior to departing for Uganda. The whole team talked through the construction, from site clearance to fit-out, allowing design queries and change requests to be prioritised quickly to maintain the programme.
The building footprint and site boundaries were marked out in full size, allowing material handling and storage areas to be identified. This identified pinch points in the programme and allowed additional storage areas to be recognised. For example, the pressing of interlocking stabilised soil blocks and concreting of the floor slabs, both requiring large amounts of loose raw materials, were taking place at once.

A review of proposed roof trusses identified that the sections proposed would be heavy and difficult to manually lift into position. The design was refined and sections reduced to decrease weight, thereby allowing them to be moved into position much more safely.

\subsection{Striking a balance}

Consider the simple example of installing a toilet facility at a Kenyan medical centre. The two common types of toilet constructed in the developing world are as follows.

- Pit latrines/vented pit latrines variants - commonly a small building constructed simply over a $6 \mathrm{~m}$ or more deep hole in the ground. They can be ventilated to reduce odour, and are sometimes referred to as a 'long drop'.

- Ecosan variants - a toilet that separates solids and liquids, liquids to ground and the solids to compost.

These are shown in Figure 4 and the material, end user and buildability are compared in Table 3 .
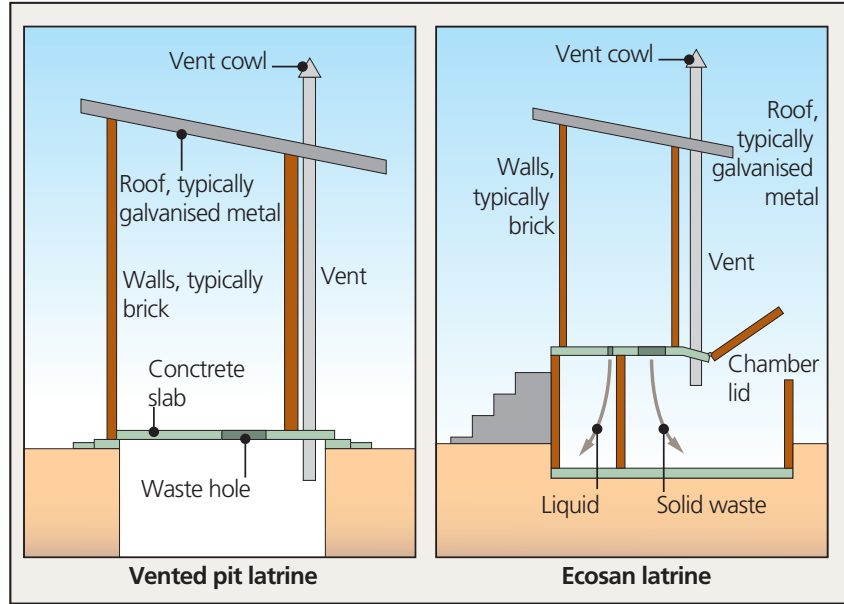

Figure 4. Pit latrine and Ecosan toilets

\begin{tabular}{|c|c|c|c|}
\hline Variant & End user & Materials & Buildability \\
\hline Pit latrines & $\begin{array}{l}\text { Likely to be limited to cleaning of flooring only. } \\
\text { Dependent on the initial capacity of the pit, the } \\
\text { frequency of re-digging will vary but not likely } \\
\text { to be frequent. }\end{array}$ & $\begin{array}{l}\text { Shelter is constructed of bricks, mortar, concrete } \\
\text { for flooring and galvanised sheets for the roof. }\end{array}$ & $\begin{array}{l}\text { This type requires a deep narrow excavation. } \\
\text { There will be working at height during } \\
\text { construction of building, but simple above- } \\
\text { ground construction. }\end{array}$ \\
\hline Ecosan & $\begin{array}{l}\text { As well as routine cleaning this would require } \\
\text { regular removal of solid waste to create } \\
\text { compost. Training on its use and how to } \\
\text { maintain would be required. }\end{array}$ & $\begin{array}{l}\text { Shelter is constructed of bricks, mortar, concrete } \\
\text { for flooring and galvanised sheets for the roof. }\end{array}$ & $\begin{array}{l}\text { There will be working at height during } \\
\text { construction of building, but simple above-ground } \\
\text { construction. Separate chambers for solid and } \\
\text { liquid waste will be required below ground level. }\end{array}$ \\
\hline
\end{tabular}

Table 3. Latrine comparison 
There is a balance between reducing risk during construction and residual risks post construction. Constructing a pit latrine involves deep excavation but requires little input during the operation, whereas the Ecosan does not require a pit but needs more intervention during the operation. This is a simplistic example, but it is necessary to weigh up where one has more control - during construction or in the day-to-day running of the structure. A lot of this will depend on the local community and its ability to adopt a maintenance regime.

Putting in place detailed maintenance procedures should not be discounted. However, training time should be factored into the planning and appropriate guidance supplied. The need for any specially trained operators should be understood and a plan should be put in place to ensure the continuation of safe working practices throughout the life cycle of the structure.

\subsection{Foundation to finish}

When designing a structure the complete build should be considered, including the finishes. What seem like the simple items in the final stages of the construction programme, such as painting of walls or ceilings, can be high-risk activities. In humanitarian work these items may not be as important as the primary structural elements and may be selected on cost and time available, but they still require consideration at the design and construction planning stage to ensure they can be applied and maintained safely.

\section{Construction planning}

Spending time on planning the construction stage is critical to safety everywhere in the world. Good planning will not only improve safety but will also have a positive impact on cost, quality and programme. During this phase a plan is produced that turns the design into a workable delivery plan. Common parts to this plan include

- programme

- cost estimate

- construction phase plan

- risk assessment and method statements

- controlled substances hazardous to health assessments.
The programme and cost estimate are primarily project management tools but suitable time and financial resources should be given to construction tasks to allow them to be completed safely. Has enough time been set aside for temporary works, for example? Does the budget allow for the construction of temporary works? It is prudent to allow a longer time for certain activities in humanitarian projects as the construction method is likely to be manual and time intensive.

A construction phase plan is required for every UK construction project (HMG, 2015: part 3, 12(1-2)), and preparing one for a humanitarian project can provide a very useful starting point for the safe planning of the construction phase. Table 4 describes the recommended sections of a construction phase plan.

\subsection{Provision of welfare}

Basic welfare should be provided and should be considered during construction planning. The impact of providing adequate welfare provision on cost and programme should not be taken lightly.

It should be assumed that toilet facilities, shade, if in a hot climate, and water point will be required. Unfortunately the hired welfare units used across the UK are very unlikely to be available, so they will have to be built, requiring design and construction planning as they can carry some significant risks, as indicated by Table 5 .

\subsection{Risk assessments and method statements}

In an ideal world, risk assessments and method statements should be carried out by those managing the work activities. On a humanitarian project this is likely to be problematic because the construction manager is not from the local area and so has a limited understanding of the techniques, capabilities and materials available. This can be illustrated using an example from a project in Uganda.

The building specification required a flood screed with a float finish to reduce the amount of dust collecting on the floor. This activity was risk assessed and a method statement produced using common UK practice; however, the preferred Ugandan method used large quantities of paraffin to achieve the required finish. This presented the site team with two risks not considered during the planning: fumes in an unventilated space and a fire risk. With the knowledge that this method is preferred locally, the design team will specify alternatives on future projects.

\begin{tabular}{|c|c|}
\hline Section & Description \\
\hline $\begin{array}{l}\text { Management } \\
\text { plan }\end{array}$ & $\begin{array}{l}\text { Details the roles and responsibilities in managing the project. Would describe any donor/charity relationship and who is managing the } \\
\text { construction site. }\end{array}$ \\
\hline $\begin{array}{l}\text { Communication } \\
\text { plan }\end{array}$ & $\begin{array}{l}\text { Details how roles described in the management plan will communicate with each other. Important to consider communication with the design } \\
\text { team if they are remote. }\end{array}$ \\
\hline $\begin{array}{l}\text { Change } \\
\text { management }\end{array}$ & $\begin{array}{l}\text { Details how design change will be managed, and who can instruct the change. Establishing a robust process is good project management but } \\
\text { will also ensure that Risk Assessment and Method Statement (RAMS) and Control of Substances Hazardous to Health (COSHH) assessments are } \\
\text { updated, allowing the changes to be safely incorporated into the construction. }\end{array}$ \\
\hline Site rules & $\begin{array}{l}\text { Details clear rules that those working on the site must follow. It will detail the clothing and PPE required as well as smoking, drugs and alcohol } \\
\text { policy. These will need to be adapted to the country and area the project is being constructed in. }\end{array}$ \\
\hline Welfare & $\begin{array}{l}\text { Details the welfare to be provided. Standards exist in the UK but are less likely to be seen in the developing world. Any specific requirements will } \\
\text { be identified through the RAMS process. Thought should be given to providing toilet facilities, and shade if in hotter climates. }\end{array}$ \\
\hline $\begin{array}{l}\text { Emergency and } \\
\text { medical plans }\end{array}$ & $\begin{array}{l}\text { Details what will happen in an emergency. Usually limited to medical incidents, but in the humanitarian sphere may need to include disease outbreaks such } \\
\text { as Ebola, or terrorist/civil unrest. Consideration should be given to the treatment of local staff and western staff as different procedures may be required. }\end{array}$ \\
\hline $\begin{array}{l}\text { Site set-up and } \\
\text { logistics plan }\end{array}$ & $\begin{array}{l}\text { Details how the site is set up, where deliveries are received and materials are stored. It will include welfare provided and the water supply points. } \\
\text { Some thought should be given to this plan as transport is often expensive. The method of construction may require large amounts of raw materials, } \\
\text { so large delivery areas and material handling areas may be needed. Consideration should be given to the interaction between vehicles and people. }\end{array}$ \\
\hline
\end{tabular}




\begin{tabular}{|c|c|c|}
\hline Item & Considerations & Potential risks / hazards \\
\hline $\begin{array}{l}\text { Shaded } \\
\text { area }\end{array}$ & $\begin{array}{l}\text { Number of people on site } \\
\text { - Orientation and time of day } \\
\text { required }\end{array}$ & working at height \\
\hline Toilet & $\begin{array}{l}\text { - Number of people on site } \\
\text { - Segregation for men and women } \\
\text { needed } \\
\text { - Groundwater sources and water } \\
\text { courses in the vicinity } \\
\text { - Hand-washing facilities required } \\
\text { - Internal lights required }\end{array}$ & $\begin{array}{l}\text { Deep excavation } \\
\text { - Working at height } \\
\text { - Handling of hazardous } \\
\text { materials }\end{array}$ \\
\hline $\begin{array}{l}\text { Water } \\
\text { point }\end{array}$ & $\begin{array}{l}\text { Distance from site } \\
\text { - Store water on site or use local } \\
\text { borehole } \\
\text { - Activities requiring water } \\
\text { (concreting, hand washing etc.) }\end{array}$ & $\begin{array}{l}\text { Disease risk } \\
\text { Manual handling - } \\
\text { moving water to and } \\
\text { from site }\end{array}$ \\
\hline $\begin{array}{l}\text { Washing } \\
\text { station }\end{array}$ & $\begin{array}{l}\text { Number of people on site } \\
\text { - Location }\end{array}$ & - Disease risk \\
\hline Store & $\begin{array}{l}\text { - Security required } \\
\text { - Location } \\
\text { - Storage of hazardous chemicals } \\
\text { or substances } \\
\text { - Internal lights required }\end{array}$ & $\begin{array}{l}\text { Working at height } \\
\text { - Handling of hazardous } \\
\text { materials } \\
\text { - Manual handling - } \\
\text { moving items to store }\end{array}$ \\
\hline $\begin{array}{l}\text { Site } \\
\text { office }\end{array}$ & $\begin{array}{l}\text { Location } \\
\text { Internal lights required? } \\
\text { - Power required (for computers, } \\
\text { printers etc.) }\end{array}$ & $\begin{array}{l}\text { Working at height } \\
\text { Electricity }\end{array}$ \\
\hline
\end{tabular}

Table 5. Standard welfare provision

\section{Construction}

Construction is where the hard work carried out during design to reduce risk will pay dividends. There are a number of ways the client can influence safety during construction. Providing adequate time and resources for thorough site set-up, procuring appropriate PPE and increasing awareness of the workforce by engaging with them through toolbox talks can all improve the chances that the workforce will go home uninjured.

In a humanitarian project it is likely that the site management is carried out by a representative of the development organisation or charity funding the project rather than a professional contractor. If this is the case then it is recommended to employ a local foreman to manage the workforce.

Through experience, having a good foreman can assist in the procurement of labour, interpreting the methodology into local practice, communicating with the workforce and aiding in safety management.

\subsection{Site set-up}

Site set-up should include the welfare identified during the construction planning (Table 5) as well as consideration of site layout, entrance and egress routes, and the surrounding environment. The level of site set-up will depend on project duration, and resources available.

Consideration of the site layout can prevent injury by reducing the likelihood of vehicle/pedestrian collisions and the common slips, trips and falls. For example, thinking about areas that workers need to access, such as the toilet and tool store, and logically setting these areas out to prevent routes through hazardous areas; directing people on a route that does not take them through an area of excavation is a simple way of reducing risk.

Attention should be paid to the local area surrounding the site. The local population, the climate and surrounding land use should be considered. The local population will determine what level of site boundary and security is required. Preventing the thievery of tools and materials may be a priority, but preventing people from injuring themselves when the site is unoccupied should also be considered. Excavations, for example, should be covered. Routes to school should be given special attention as a humanitarian project can attract crowds of curious children. A potential mitigation is to view the local people movements and programme works to avoid peak traffic times.

The local climate clearly has a big impact on any construction works, with heavy rainfall and flooding causing delays, or high temperatures affecting the quality of concrete. Local weather patterns can also have a big impact on safety, and risk assessments and method statements should be reviewed with changing conditions. Looking at examples of work already outlined in this paper, is erecting roof trusses sensible in high winds, or heavy rainfall? Would using paraffin in hot dry conditions be sensible?

Heavy rainfall is a particular hazard; the heavy clay soil on which the grain store in Uganda was constructed, for example, was impermeable, and the frequent heavy storms during the construction period caused significant localised flooding and led to the creation of French drains around the new building to prevent damage and the erosion of neighbouring farmland. Scheduling work around daily rainfall and putting activities on hold until conditions improve are simple ways to mitigate the impact of weather. If there is significant overland flow, drains may need to be dug to channel water away from work areas.

\subsection{Toolbox talks}

It is common practice on UK sites to use regular targeted toolbox talks to refresh understanding of risks and the control measures put in place to control them. As discussed previously, workers in the developing world are not aware of the majority of construction risks, for example the common practice of using cement packaging as makeshift sun hats.

Engineers for Overseas Development is looking at developing a series of simple toolbox talks to raise risk awareness.

\subsection{Personal protective equipment}

The use of PPE is at the lower end of the hierarchy of risk control (Table 2), but still plays an important role in safety. On a humanitarian project it is unreasonable to enforce strict PPE rules and good quality safety equipment is likely to be expensive or unavailable.

In Uganda a policy of using appropriate PPE was adopted, where each task was reviewed and key PPE identified as opposed to a blanket application. For example, gloves, eye protection and wellingtons were provided to those concreting. Other measures that can be adopted to counter the lack of PPE include maintaining good housekeeping and providing good hand/eye washing facilities.

As there is likely to be a limited amount of plant and number of vehicles on site during the construction, hi-visibility vests will have a limited safety application, but they were found to provide a useful tool to identify who was working on site and would be paid at the end of each working day, and became almost a uniform for the workers. 


\subsection{Setting the example}

The need to set the example cannot be emphasised enough. This is magnified in humanitarian work as all eyes are on the western engineer for guidance. Project management behaviour is likely to be mimicked and carried to other sites after the project has finished. Being rigorous and robust in implementing safety should be tempered with patience. Project managers should be patient and explain the risks and why the controls are put in place and maintained. This can provide huge benefits, not only in safety, but productivity and worker morale.

Figure 5 shows the result of 14 weeks of good site safety practice, where the workforce took it upon themselves to think about the safety of others.

\section{Post construction}

Safety does not stop with the completion of construction, as the safety of operators and maintainers needs to be considered. Where possible these groups should have been involved at the early stages of design and their needs should certainly be considered by the designer.

Thought should be given to how the handover from the construction team to the community or operator will take place, and what form the information will take. Before completion, it should be determined what information is required by these groups immediately on completion and in the future to safely carry out their roles. Consideration should be given to the language the information is provided in and whether it can be presented pictorially to aid understanding.

Clear training should be given to those taking over and any residual risks that remain need to be highlighted during the handover. Throughout the design, efforts have been made to simplify maintenance by making easily accessible items that will require replacements, and by simplifying the design to make critical items maintainable. If items have specific requirements or need parts from a specific place, this information should be communicated to the person or people who will be taking over maintenance.

It is recommended that the construction team carry out a review of the structure before handing over, to confirm that all residual risks are identified and that suitable control measures are in place.

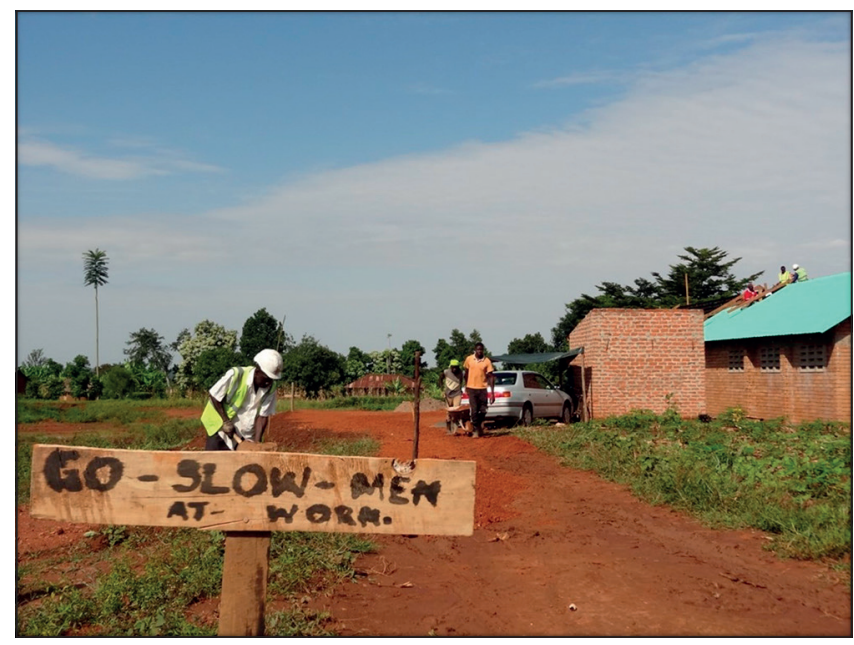

Figure 5. 'Slow men at work' picture

\section{Appling CDM principles to humanitarian projects.}

The 2015 incarnation of the CDM regulations applies to all UK construction projects. They seek to instil a clear ethos of safety responsibility in all members of the project team, providing clarity on roles and responsibility in the management of risk. Applying the regulations in full to humanitarian projects is in most cases not appropriate, but the principles of the regulations can and should be applied.

The considerations described throughout this paper follow the ethos of CDM, through the early consideration of risk, the passage of information to end users and setting out a clear management structure. The application of all safety measures and controls should be proportional to the risk and should not burden those working on any project with undue process. Box ticking and paperwork exercises can be a risk in themselves.

\section{Summary}

This paper has looked at safety considerations throughout the project lifecycle: applying the principles of CDM, considering risk early, communicating remaining risks, and above all making responses proportionate to the risk.

Safety should be considered throughout any project, right from the initial idea through construction to the day-to-day operation. The earlier risks are identified and understood, the quicker and cheaper they can be mitigated. The decisions made when selecting options and design can have a large impact on safety both during and after construction.

The client and designer must identify, understand and consider the needs of those constructing, operating and maintaining the structure, and effectively design out risk. Time and effort needs to be put into planning the construction phase. Determining what is needed, who is needed and how the work is going to be done is crucial not only to manage costs and the programme, but to managing safely.

Construction is a dangerous industry in any country, but especially so in developing countries with a poor safety culture and a low risk awareness. It is the duty of all those designing, specifying and constructing humanitarian projects to consider the safety of workers and those who will come after the construction.

\section{References}

CITB (Construction Industry Training Board) (2016) Changes to Health and Safety Regs: Construction (Design and Management) Regulations 2015 CITB, Kings Lynn, UK. See http://www.citb.co.uk/health-safety-and-othertopics/health-safety/construction-design-and-management-regulations/ (accessed 11/03/2016)

HMG (Her Majesty's Government) (2015) Health and Safety. The Construction (Design and Management) Regulations 2015. The Stationery Office, London, UK, Statutory Instrument 2015 No. 51.

HSE (Health and Safety Executive) (2014) Health and Safety in Construction Sector in Great Britain, 2014/15. HSE, Bootle, UK. See http://www.hse.gov.uk/Statistics/industry/construction/construction.pdf (accessed 09/08/2015) 